\title{
Gastrointestinal lymphoma: the new mimic
}

\author{
Anusha Shirwaikar Thomas, ${ }^{\oplus 1}$ Mary Schwartz, ${ }^{2}$ Eamonn Quigley ${ }^{2}$
}

To cite: Shirwaikar Thomas A, Schwartz M, Quigley E. Gastrointestinal lymphoma: the new mimic. BMJ Open Gastro 2019;6:e000320. doi:10.1136/ bmjgast-2019-000320

The material in the paper was previously presented as an abstract at the WCG meeting in Orlando in 2017.

Received 11 June 2019 Revised 21 August 2019 Accepted 27 August 2019

Check for updates

(c) Author(s) (or their employer(s)) 2019. Re-use permitted under CC BY-NC. No commercial re-use. See rights and permissions. Published by BMJ.

${ }^{1}$ Department of Gastroenterology, University of Texas MD Anderson Cancer Center, Houston, Texas, USA ${ }^{2}$ Hepatology and Nutrition, Houston Methodist Hospital, Houston, Texas, USA

Correspondence to Dr Anusha Shirwaikar Thomas; ASThomas1@mdanderson.org

\section{ABSTRACT}

Background Gastrointestinal (Gl) lymphomas comprise a group of distinct clinicopathological entities of B- or T- cell type, with primary gastrointestinal Hodgkin lymphoma being extremely uncommon. The Gl tract is the predominant site of extranodal non-Hodgkin lymphoma accounting for $30-40 \%$ of all extranodal lymphomas. In the Western world, the stomach is the most commonly involved site followed by the small bowel. Several chronic inflammatory and immune-mediated disorders which predispose to accelerated cell turnover may lead to the malignant transformation of gut lymphocytes and ultimately manifest as Gl lymphoma. The challenge for the clinical gastroenterologist is that these tumors may have varied presentations, ranging from nonspecific symptoms such as dyspepsia or bloating to abdominal pain, nausea, vomiting, Gl bleeding, diarrhea, weight loss or bowel obstruction.

Objective We illustrate the range of presentations of $\mathrm{Gl}$ lymphoma with examples based on consecutive cases evaluated at our institution over a 6 -month period. These cases demonstrate how appropriately directed endoscopic evaluation with biopsies has the potential to provide a definitive diagnosis and allow the patient to proceed to definitive therapy.

Conclusions The $\mathrm{Gl}$ tract is the most commonly involved site for extranodal lymphoma with the stomach being most frequently involved organ.Chronic Helicobacter pylori infection, celiac disease, inflammatory bowel disease and autoimmune disorders may predispose to Gl lymphoma. This heterogenous group of diseases has varied presentations that may mimic several other Gl clinicopathologic entities. Gl lymphomas may be diagnosed with appropriately directed endoscopic evaluation coupled with generous tissue sampling and expert pathologic assessment. Management may range from antibiotic therapy, in the case of Helicobacter pylori-associated gastric MALT Iymphoma, to chemotherapy with or without radiation and, in rare instances, surgery. There are presently no guidelines to direct endoscopic surveillance of Gl lymphomas following treatment.

\section{INTRODUCTION}

The gastrointestinal (GI) mucosal surface functions as a variably permeable barrier subserving its roles in secretion and absorption along the length of the gut. Its surface area is greatly increased through various anatomical and ultrastructural features (folds, villi and microvilli). This facilitates its access to the products of digestion as well as exposure to a significant antigenic load from microorganisms and ingested materials in the lumen. The mucus layer on the mucosal surface, together with the epithelium (gut barrier), serves as the first line of defence against pathogens and other potentially injurious invaders. More specific immunological responses are generated by the gut or mucosa-associated lymphoid tissue (MALT) in the epithelium and lamina propria. These lymphoid cells are produced in the bone marrow and thymus and migrate to the gut to form one of the largest collections of immune cells in the body. ${ }^{1}$ MALT, through its unique immunophysiological characteristics, serves to maintain immune homeostasis in the intestine. The most distinctive and visible aggregation of lymphoid tissue in the GI tract is found in the Peyer's patches in the terminal ileum; the remainder is diffusely distributed in the form of lymphoid aggregates in the lamina propria throughout the entire GI tract. ${ }^{2}$ Repetitive inflammation and antigenic stimulation in response to autoimmune and inflammatory disorders can lead to monoclonal proliferation and the development of extranodal GI lymphomas over time. For example, chronic Helicobacter pylori infection in the gastric mucosa, typically devoid of MALT, may lead to lymphoid cell proliferation. ${ }^{3}$ Malignant transformation of this acquired gastric MALT results in an indolent MALT lymphoma which may be treated simply by eradication of the underlying chronic infection. ${ }^{4}$ Among those with a hereditary sensitivity to gluten, that is, coeliac disease, gluten peptides presented by HLADQ2 and HLADQ8-positive antigen presenting cells elicit an immune response leading to destruction of the intestinal epithelium by intraepithelial T-cell lymphocytes. ${ }^{5}$ Malignant transformation of these cells can lead to an aggressive enteropathy-associated T-cell lymphoma (EATL) of the small bowel. ${ }^{6}$ Autoimmune disorders such as systemic lupus 
erythematosus have been associated with the development of GI lymphoma; immunosuppression, rather than the disease process itself, confers this risk in this patient population. Additionally, congenital syndrome as well as AIDS predisposes to the development of lymphomas. ${ }^{7}$ Thiopurines and anti-tumour necrosis factor therapies, such as those employed in the management of patients with inflammatory bowel disease (IBD), also increase the risk of developing lymphoma. ${ }^{8-10}$ Young males under the age of 35 on thiopurine therapy for IBD seem to be especially at risk for the development of hepatosplenic T-cell lymphoma. ${ }^{11}$

\section{Epidemiology}

The WHO broadly classifies lymphoid neoplasms as precursor lymphoid neoplasms, mature B-cell neoplasms, mature T-cell and natural killer cell neoplasms, and Hodgkin's lymphomas based on distinctive pathological and genetic features. ${ }^{12}$ Extranodal Hodgkin's lymphoma is exceedingly rare. Extranodal GI B-cell lymphomas are more common (contributing $80 \%$ of the total) than T-cell lymphomas, are more responsive to chemotherapy and have a better overall prognosis. ${ }^{13}$ Most lymphomas demonstrate fairly typical architectural features and specific cytogenetic abnormalities which aid in pathological diagnosis.

GI lymphomas constitute 1\%-4\% of all GI malignancies, $10 \%-15 \%$ of all non-Hodgkin's lymphomas (NHL), and $30 \%-40 \%$ of all extranodal NHLs, making the GI tract the most common site for extranodal lymphoma. ${ }^{14}$ In terms of anatomical location the most common site is the stomach, followed by small bowel and colorectum; oesophageal lymphoma is exceptionally rare. ${ }^{15}{ }^{16}$ In one large study of primary GI NHLs, the anatomical distribution was as follows: gastric - $74.8 \%$, small bowel- $8.6 \%$ and ileocaecal-7.0\%. Multiple locations were noted in $6.5 \% .{ }^{17}$

Typically, GI lymphomas present in the sixth decade of life and are slightly more common in males. ${ }^{18}$ The challenge for the clinical gastroenterologist is that these tumours may present in very varied ways, ranging from non-specific symptoms such as dyspepsia or bloating to abdominal pain, nausea, emesis, GI bleeding, diarrhoea, weight loss or bowel obstruction. Appropriately directed endoscopic evaluation with biopsies has the potential to provide a definitive diagnosis and allow the patient to proceed to definitive therapy. Routine histology, immunohistochemistry, flow cytometry, in situ hybridisation, and fluorescent in situ hybridisation can all be performed on biopsies to provide the detailed information needed for optimal therapy.

\section{METHODS}

To exemplify the range of presentations of GI lymphoma and to illustrate the important role of the gastroenterologist in its assessment, we present a series of cases of GI lymphomas seen at our institution between January and June 2017 (table 1). We identified 16 individual cases that were diagnosed by various gastroenterologists during this time period. Illustrative clinical and endoscopic features are provided.

\begin{tabular}{|c|c|c|}
\hline Gender & Clinical presentation & Endoscopy \\
\hline Female & Dyspepsia & Antral 'gastritis', duodenitis \\
\hline Male & Positive stool DNA testing & Ulcerated mass at splenic flexure and ascending colon \\
\hline Male & Food impaction, dysphagia & Clean-based gastric ulcers \\
\hline Male & Gastric outlet obstruction & $\begin{array}{l}\text { Fungating, infiltrative, ulcerated circumferential mass in gastric } \\
\text { body }\end{array}$ \\
\hline Female & Haematemesis & Large cratered necrotic duodenal ulcer \\
\hline Male & Intussusception at terminal ileum (TI) & Partially obstructing mass at the ileocaecal valve \\
\hline Male & Abdominal pain & $\begin{array}{l}\text { Fungating, partially obstructing mass in ascending colon and } \\
\text { caecum }\end{array}$ \\
\hline Female & Abdominal pain & Partially obstructing tumour in the caecum \\
\hline Male & Abnormal abdominal imaging, anaemia & Partially obstructing mass at the ileocaecal valve \\
\hline Female & $\begin{array}{l}\text { Profound hypoalbuminaemia (malnutrition), } \\
\text { anasarca }\end{array}$ & Mucosal changes in jejunum \\
\hline Male & Severe anaemia, abdominal pain & $\begin{array}{l}\text { Non-obstructing, circumferential, polypoid mass in the terminal } \\
\text { ileum }\end{array}$ \\
\hline Female & Iron deficiency anaemia & Large, ulcerated, non-obstructing mass at ileocaecal valve \\
\hline
\end{tabular}




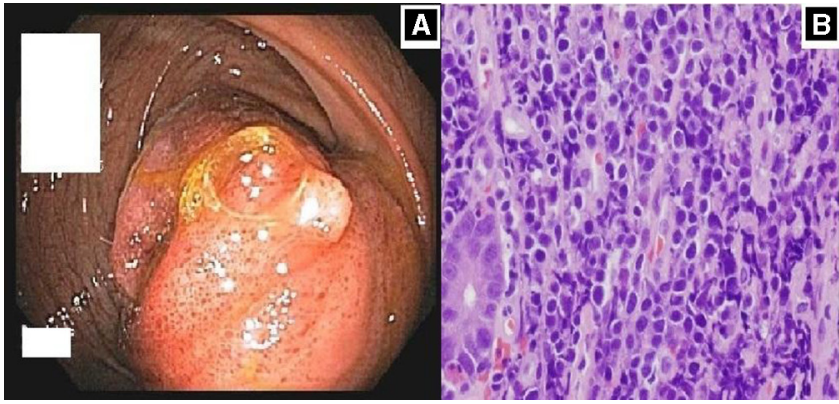

Figure 1 (A) Partially obstructing mass at ileocecal valve. (B) High grade $B$ cell lymphoma

\section{Illustrative clinical presentations}

Abdominal pain

Approximately $45 \%-65 \%$ of all cases of GI lymphomas present clinically with abdominal pain due to a mass or bowel obstruction, as illustrated by the following three patients. ${ }^{15-18}$

- A man presented with abdominal pain for several weeks and imaging findings of intussusception due to a caecal mass. Colonoscopy showed a partially obstructing mass at the ileocaecal valve (figure 1A). Biopsies demonstrated a high-grade B-cell lymphoma (figure 1B).

- A man on therapy for H. pylori-associated chronic gastritis was evaluated for progressive severe right lower quadrant pain. CT of the abdomen showed focal thickening in the terminal ileum with associated mesenteric lymphadenopathy. Colonoscopic evaluation demonstrated a multilobulated ulcerated polypoid lesion at the ileocaecal valve (figure $2 \mathrm{~A}$ ) as well as a large fungating, polypoid, ulcerated, non-obstructing mass in the distal ileum (figure 2B). Biopsies of both lesions showed large B-cell lymphoma.

- A woman with a history of anal cancer treated by chemoradiation and complicated by an anal stricture was hospitalised with progressive right lower abdominal pain. Abdominal imaging with CT revealed the presence of a caecal mass with adjacent lymphadenopathy (figure 3A). Colonoscopic evaluation demonstrated a malignant appearing partially obstructing tumour in the caecum (figure $3 \mathrm{~B}$ ) and biopsies showed Epstein-Barr virus-positive Burkitt lymphoma (figure 3C).

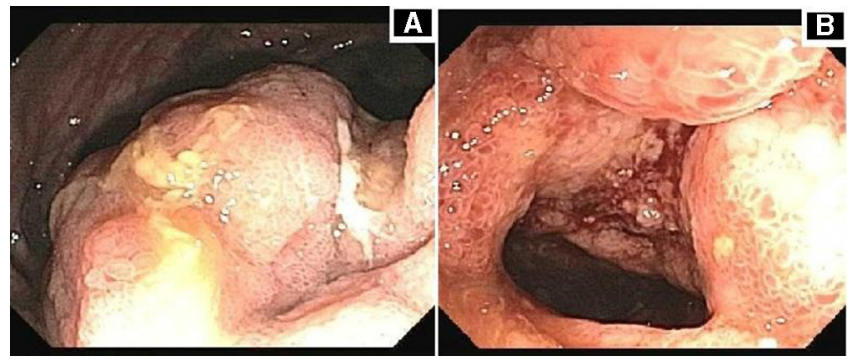

Figure 2 (A) Multilobulated ulcerated polypoid lesion at the ileocaecal valve. (B) A large fungating, polypoid, ulcerated, non-obstructing mass in the distal ileum

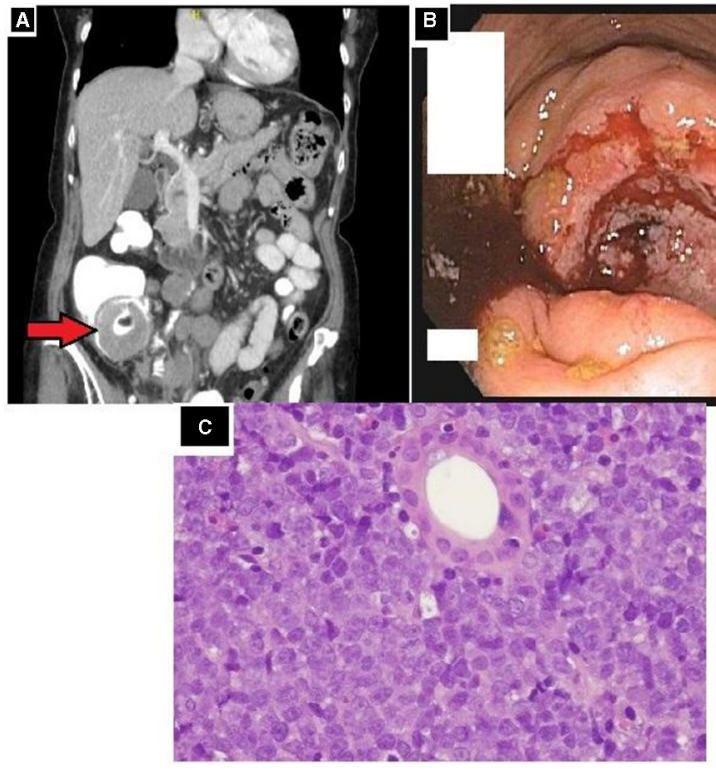

Figure 3 (A) A caecal mass with adjacent lymphadenopathy on contrasted abdominal imaging. (B) Malignant appearing partially obstructing cecal tumor. (C) EBV positive Burkitt Lymphoma.

\section{Diarrhoea}

- A man with hemochromatosis complicated with portopulmonary hypertension and common variable immunodeficiency syndrome on intravenous immunoglobulin replacement and idiopathic thrombocytopenia on high-dose steroids was evaluated for chronic non-bloody diarrhoea and weight loss for 3 months.

Colonoscopy showed several polyps in the transverse colon, hepatic flexure, ascending colon and caecum that were biopsied (figure 4A,B). Biopsies from the hepatic flexure polyp demonstrated marginal zone lymphoma with focal transformation to diffuse large B-cell lymphoma (DLBL).

\section{Gl haemorrhage}

- A woman presented with massive haematemesis. Oesophagogastroduodenoscopy (EGD) was remarkable for a large cratered necrotic duodenal ulcer (figure 5A, arrowed) and CT of the abdomen revealed marked thickening of the duodenal wall (figure 5B, arrowed). Biopsies demonstrated large B-cell lymphoma (figure 5C).

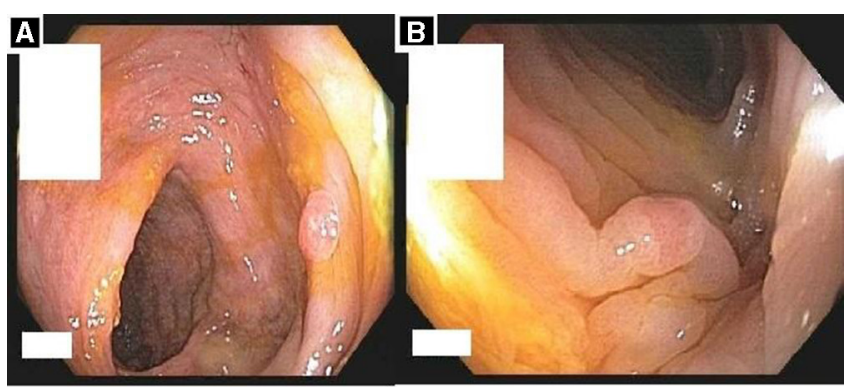

Figure 4 Benign appearing colon polyps. 


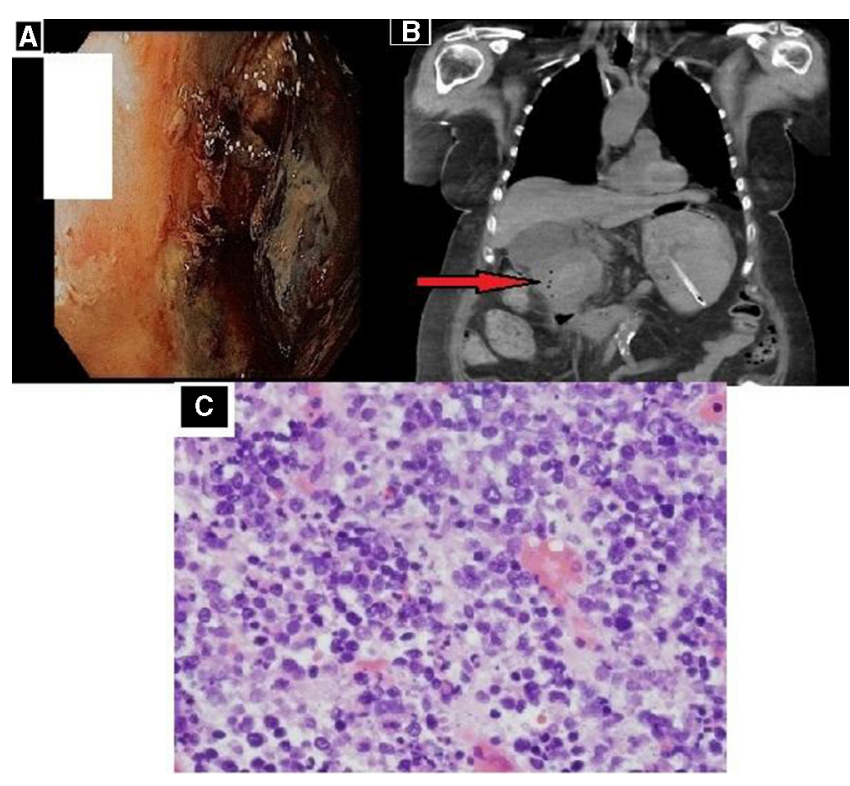

Figure 5 (A) Large cratered necrotic duodenal ulcer. (B) Marked duodenal wall thickening on contrasted abdominal imaging. (C) Large B- cell lymphoma.

- A man was admitted with overt melena and progressive symptomatic anaemia for a week; evaluation by upper endoscopy showed a large, fungating, infiltrative and ulcerated circumferential mass in the gastric fundus (also seen on imaging of the abdomen-figure 6A) in addition to congested, granular, nodular and ulcerated mucosa of the entire stomach (figure 6B); biopsies demonstrated DLBL (figure 6C).

Non-specific upper Gl symptoms

- A woman was evaluated with upper endoscopy (EGD) for dyspepsia. Findings included non-specific erythema and erosions in the stomach and duodenal bulb (figure 7A,B). Antral biopsies demonstrated low-grade B-cell lymphoma.

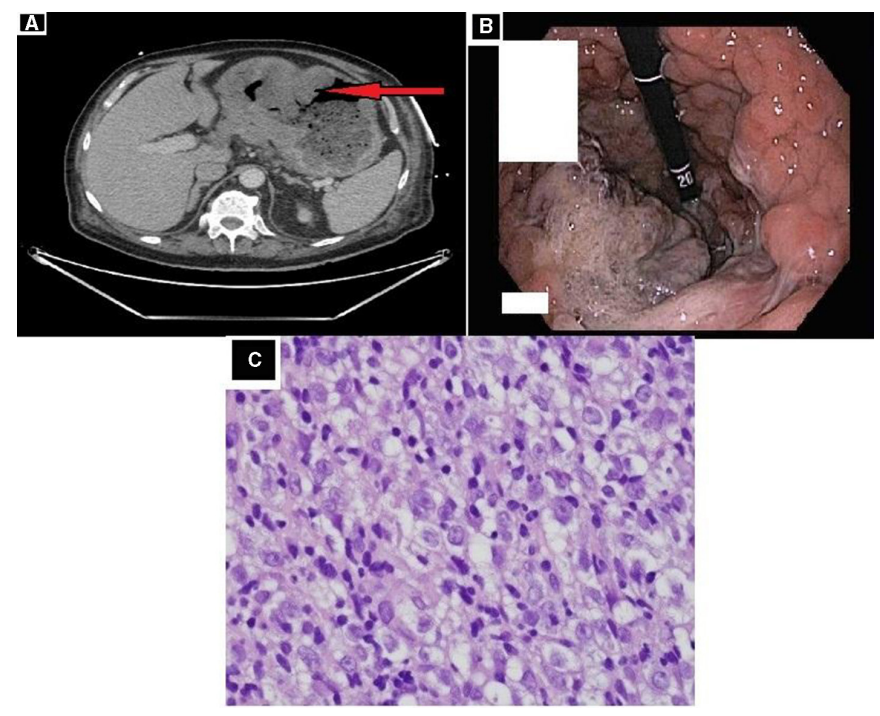

Figure 6 (A) Mass in the gastric fundus on contrasted abdominal imaging. (B) Large, fungating, infiltrative mass in fundus . (C) Diffuse large B cell lymphoma.

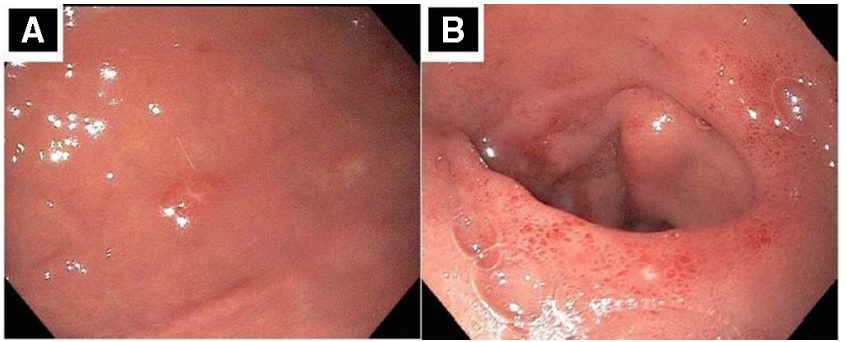

Figure 7 Non specific gastric erosions and duodenal bulb erythema.

- A man with a remote history of treated $H$. pylori-associated peptic ulcer disease was admitted with early satiety accompanied by nausea, emesis and significant weight loss. CT of the abdomen showed a large gastric mass with direct invasion into the left lobe of the liver suspicious for malignancy (figure 8A); an upper endoscopy showed a large fungating, infiltrative and ulcerated circumferential mass in the body of the stomach (figure 8B); biopsies demonstrated DLBL (H. pylori negative).

\section{Gastric ulceration}

- A man presented with a food impaction; EGD showed a non-obstructive Schatzki's ring, erythematous gastric mucosa and multiple clean-based ulcers in the stomach and duodenum (figure 9A,B). Biopsies demonstrated $H$. pylori-associated chronic active gastritis and extranodal marginal zone lymphoma of mucosal associated lymphoid tissue (MALT lymphoma) (figure 9C). He completed a course of treatment for $\mathrm{H}$. pylori with complete resolution of the lymphoma on repeat endoscopic evaluation.

\section{DISCUSSION}

Clinical features by anatomical location

Oesophageal lymphoma

Primary oesophageal lymphoma is very rare comprising less than $1 \%$ of all primary GI lymphomas. Oesophageal involvement is usually secondary to spread from cervical or mediastinal lymph nodes. ${ }^{19}$ Clinically, patients may present with dysphagia, weight loss, dyspepsia or upper GI bleeding. Endoscopically, these tumours may have a

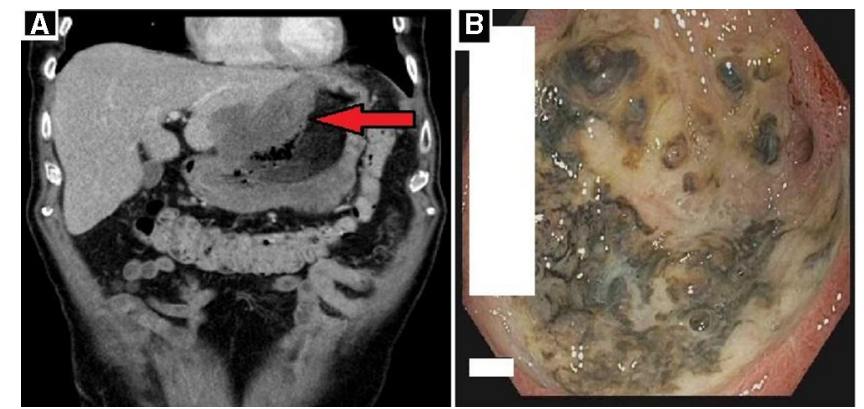

Figure 8 (A) Large gastric mass with direct invasion into left lobe of liver on contrasted abdominal imaging. (B) Fungating, ulcerated mass in gastric body. (C) Diffuse large $B$ cell lymphoma. 


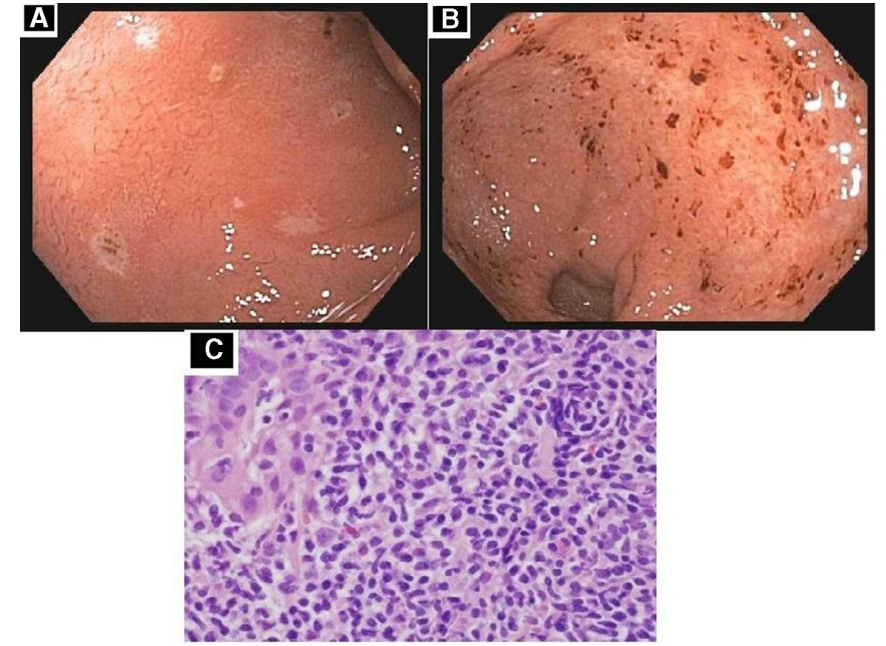

Figure 9 (A, B) Clean based antral and duodenal bulb ulcers. (C) MALT Iymphoma.

nodular, polypoidal, ulcerated or stenotic appearance. Endoscopic ultrasound may be employed to assess the depth of tumour invasion. ${ }^{20}$

\section{Gastric lymphoma}

The stomach is the most frequently involved GI site among GI lymphomas. MALT lymphoma is the most common subtype followed by DLBL. ${ }^{21}$ A small proportion of patients with $H$. pylori infection may develop MALT lymphoma. The bacterial infection may trigger activation of CD4 $\mathrm{T}$ cells and indirectly stimulate B cells and, thereby, lead to the development of a malignancy. ${ }^{22}$ Additionally, it has been noted that individuals with the $\mathrm{t}(11 ; 18)(\mathrm{q} 21 ; \mathrm{q} 21)$ translocation appear to have a higher predisposition to develop MALT lymphoma. ${ }^{23}$ Clinically, these patients may report abdominal pain, nausea, vomiting or present with upper GI bleeding. ${ }^{21} 24$ The endoscopic appearance of MALT lymphomas is variable ranging from an exophytic ulcerated mass to hypertrophic and enlarged gastric folds or hyperaemic changes in gastric mucosa, ${ }^{24}$ as illustrated by case 9 .

Though less common than MALT lymphoma, gastric DLBL has also been observed to be associated with $H$. pylori infection and reported to express CD19, CD20, CD22 and CD79. ${ }^{26} 27$ They may present with symptoms similar to MALT lymphoma. Endoscopically, they are often located in the gastric body/fundus and may appear as an ulcerated lesion or a polypoid mass or diffuse/focal thickening of the gastric wall (cases 5, 6, 8) ${ }^{26}$

\section{Intestinal lymphoma}

The small bowel and large bowel are the second most commonly affected sites, with the ileum most often involved. Various lymphoma subtypes found in the intestines include MALT, DLBL, mantle cell lymphoma (MCL), follicular lymphoma (FL) and intestinal T-cell lymphoma. ${ }^{14-18} 2829$ Patients may present with fever, abdominal pain, diarrhoea, haematochezia and weight loss (cases 1, 3, 4). CT of the abdomen may display bowel wall thickening, obstruction or mucosal ulceration. ${ }^{14-18}$ 28-30 Capsule endoscopy and colonoscopy are used to detect these tumours which may appear as ulcerated lesions or diffuse mucosal thickening with coarse or fine granular appearance. ${ }^{31}$ The latter is especially useful due to the predilection of lymphoma to the distal ileum and ileocaecal areas. ${ }^{31}$

\section{Lymphoma of gall bladder, biliary tree, pancreas and liver}

While our focus has been on lymphoma involving the oesophagus, stomach, small intestine and colon we should note that other components of the digestive system may also give rise to primary lymphomas. Primary lymphoma of the gall bladder, most commonly a MALT lymphoma or DLBL, is very rare and typically present as right upper quadrant pain. ${ }^{32-35}$ MALT lymphomas arising in the bile duct at the hilum have also been described as having extremely rare instances of B-cell lymphoma, follicular lymphoma and lymphoblastic lymphoma. Clinically, cholangiocarcinoma, primary sclerosing cholangitis or pancreatitis is the initial diagnosis with the true nature of the pathology being discovered at surgery. ${ }^{35} 36$ Primary pancreatic lymphomas account for less than $0.5 \%$ of all malignant pancreatic neoplasms and are usually diffuse $\mathrm{B}$ cell in morphology and most commonly present as a mass in the pancreatic head. ${ }^{37}$ While secondary involvement of the liver by lymphoma is common, primary hepatic lymphomas comprise $0.016 \%$ of all instances of NHL. Righty upper quadrant pain, fever and weight loss are common presenting symptoms, and hepatomegaly, rather than jaundice the main physical sign. Again B-cell morphology dominates. ${ }^{38}$

\section{Management}

Various strategies and modalities of treatment are employed in the management of GI lymphomas based on the area of involvement, histological type and clinical staging. ${ }^{12} 3940$ For example, early-stage follicular lymphoma follows an indolent course and may be followed clinically with a 'watch and wait' policy. ${ }^{41}$ Indeed, a retrospective study by Young and colleagues noted a similar overall 7.5-year survival rate among those with follicular lymphoma that underwent watchful waiting or aggressive combined modality treatment. ${ }^{42}$

More than $70 \%$ of patients with early-stage (Ann Arbor Classification Stages I-II ) MALT lymphomas associated with $H$. pylori infection can achieve remission with triple or quadruple eradication therapy alone, ${ }^{4344}$ with a tumour location, patient ethnicity, depth of invasion and molecular feature all influencing response rates. ${ }^{24}$ Radiation therapy and chemotherapy are reserved for advanced tumours and non-responders. Surgery should prove necessary only in instances of perforation or where haemorrhage cannot be controlled endoscopically. ${ }^{45}$ With regard to follow-up, it is recommended that endoscopy with careful inspection and biopsy of the previously affected area is recommended at six monthly intervals for the first 6 months and yearly thereafter. ${ }^{45}$ For non- $H$. 
pylori-associated MALT lymphomas, there is currently a lack of consensus on optimal initial therapeutic mode with both radiation therapy and chemotherapy being employed. ${ }^{46}$

For DLBLs of the stomach and intestine the consensus is that chemotherapy incorporating rituximab-cyclophosphamide-oncovin-prednisolone should be the standard regimen. ${ }^{45}{ }^{47-49}$ Here again, surgery is restricted to the management of complications such as perforation and haemorrhage. ${ }^{45}$ In the past, surgical resection was widely employed in the management of patients with GI lymphoma ${ }^{50}$; greater accuracy in preoperative diagnosis should minimise the need for surgical intervention nowadays, even in instances of intestinal obstruction, as illustrated by our case 1 , where chemotherapy induced complete resolution of an obstructing tumour.

The prognosis for intestinal T-cell lymphomas, in general, and for EATL type I (ie, that associated with coeliac disease) and monomorphic epitheliotropic intestinal T-cell lymphoma (formerly referred to as EATL type II), in particular, is poor and management strategies for these and other rare forms of GI lymphoma vary according to presentation, location, stage and histological type and may involve chemotherapy, radiation therapy, immunotherapy, surgery and autologous stem cell transplantation. ${ }^{51-53}$ In one study which included a variety of peripheral T-cell lymphomas the response rate to cyclophosphamide-oncovin-prednisolone at a median follow-up of 27 months was $62 \% .^{54}$

One complication of chemotherapy that the gastroenterologist should be aware of is intestinal perforation. In one series of 1062 patients with histologically proven GI lymphoma 9\% developed a perforation with just over one-half of these occurring after commencement of chemotherapy. The median time to perforation following initiation of chemotherapy was 46 days, most commonly involved the small intestine; aggressive B-cell histology was an important risk factor. ${ }^{55}$

With the exception of the surveillance strategy outlined above for following patients with $H$. pylori-associated T-cell lymphoma there are no guidelines for the endoscopic surveillance of patients following successful treatment of other gastric, small intestinal or colonic lymphomas. The role of endoscopic ultrasound in the follow-up of gastric lymphoma is yet to be defined.$^{56}$ Nor are there guidelines for surveillance of at-risk individuals such as those with disorders associated with an increased risk for lymphoma, such as coeliac disease ${ }^{57}$ or nodular lymphoid hyperplasia. ${ }^{559}$

Contributors AST and EQ conceived the idea for the study and planned the study. AST collated the clinical and endoscopic data. MS collated and reviewed all pathology. AST drafted the manuscript which EQ and MS edited. All three authors reviewed and approved the final manuscript.

Funding This study was supported in part by a bequest to the Lynda $K$ and David M Underwood Center for Digestive Disorders and the Josephine Hughes Sterling Foundation.

Competing interests None declared.

Patient consent for publication Not required.
Provenance and peer review Not commissioned; externally peer reviewed.

Data availability statement There are no data in this work.

Open access This is an open access article distributed in accordance with the Creative Commons Attribution Non Commercial (CC BY-NC 4.0) license, which permits others to distribute, remix, adapt, build upon this work non-commercially, and license their derivative works on different terms, provided the original work is properly cited, appropriate credit is given, any changes made indicated, and the use is non-commercial. See: http://creativecommons.org/licenses/by-nc/4.0/.

\section{REFERENCES}

1. Bienenstock J. Gut and bronchus associated lymphoid tissue: an overview. Adv Exp Med Biol 1982;149:471-7.

2. Akirav EM, Alonso-Gonzalez N, Truman LA. Lymphoid Tissues and Organs. In: Paul WE, ed. Fundamental immunology. 7th edn. Philadelphia: Lippincott Williams and Wilkins, 2013: 47-66.

3. Nagai S, Mimuro H, Yamada T, et al. Role of Peyer's patches in the induction of Helicobacter pylori-induced gastritis. Proc Natl Acad Sci U S A 2007;104:8971-6.

4. Wotherspoon AC, Diss TC, Pan L, et al. Regression of primary low-grade B-cell gastric lymphoma of mucosa-associated lymphoid tissue type after eradication of Helicobacter pylori. Lancet 1993;342:575-7.

5. Fasano A, Catassi C. Clinical practice. celiac disease. N Engl J Med 2012;367:2419-26

6. Cellier C, Delabesse E, Helmer C, et al. Refractory sprue, coeliac disease, and enteropathy-associate T-cell lymphoma. French coeliac disease Study Group. Lancet 2000;356:203-8.

7. Sandler AS, Kaplan LD. Diagnosis and management of systemic non-Hodgkin's lymphoma in HIV disease. Hematol Oncol Clin North Am 1996;10:1111-24.

8. Kotlyar DS, Lewis JD, Beaugerie L, et al. Risk of lymphoma in patients with inflammatory bowel disease treated with azathioprine and 6-mercaptopurine: a meta-analysis. Clin Gastroenterol Hepatol 2015;13:847-58.

9. Kotlyar DS, Osterman MT, Diamond RH, et al. A systematic review of factors that contribute to hepatosplenic T-cell lymphoma in patients with inflammatory bowel disease. Clin Gastroenterol Hepatol 2011;9:36-41.

10. Hanauer SB, Feagan BG, Lichtenstein GR, et al. Maintenance infliximab for Crohn's disease: the accent I randomised trial. Lancet 2002;359:1541-9.

11. Colombel J-F, Loftus EV, Tremaine WJ, et al. The safety profile of infliximab in patients with Crohn's disease: the Mayo clinic experience in 500 patients. Gastroenterology 2004;126:19-31.

12. Swerdlow SH. WHO classification of tumours of haematopoietic and lymphoid tissues. revised. 4th edn. Lyon, France: International Agency on Research on Cancer (IARC) Press, 2017.

13. Groves FD, Linet MS, Travis LB, et al. Cancer surveillance series: non-Hodgkin's lymphoma incidence by histologic subtype in the United States from 1978 through 1995. J Natl Cancer Inst 2000;92:1240-51.

14. Bautista-Quach MA, Ake CD, Chen M, et al. Gastrointestinal lymphomas: morphology, immunophenotype and molecular features. $J$ Gastrointest Oncol 2012;3:209-25.

15. Morton JE, Leyland MJ, Vaughan Hudson G, et al. Primary gastrointestinal non-Hodgkin's lymphoma: a review of 175 British National lymphoma investigation cases. Br J Cancer 1993:67:776-82.

16. Peng JC, Zhong L, Ran ZH. Primary lymphomas in the gastrointestinal tract. J Dig Dis 2015;16:169-76.

17. Koch P, del Valle F, Berdel WE, et al. Primary Gastrointestinal NonHodgkin's Lymphoma: I. Anatomic and Histologic Distribution, Clinical Features, and Survival Data of 371 Patients Registered in the German Multicenter Study GIT NHL 01/92. J Clin Oncol 2001;19:3861-73.

18. Cardona DM, Layne A, Lagoo AS. Lymphomas of the gastrointestinal tract - pathophysiology, pathology, and differential diagnosis. Indian J Pathol Microbiol 2012;55:1-16.

19. Weeratunge $\mathrm{CN}$, Bolivar $\mathrm{HH}$, Anstead GM, et al. Primary esophageal lymphoma: a diagnostic challenge in acquired immunodeficiency Syndrome-Two case reports and review. South Med $J$ 2004;97:383-7.

20. Zhu Q, Xu B, Xu K, et al. Primary non-Hodgkin's lymphoma in the esophagus. J Dig Dis 2008;9:241-4.

21. Fischbach W. Gastric MALT lymphoma - update on diagnosis and treatment. Best Pract Res Clin Gastroenterol 2014;28:1069-77. 
22. Du M-Q, Isaccson PG. Gastric MALT Iymphoma: from aetiology to treatment. Lancet Oncol 2002;3:97-104.

23. Nakamura S, Matsumoto $T$, Nakamura S. Chromosomal translocation $\mathrm{t}(11 ; 18)(\mathrm{q} 21 ; \mathrm{q} 21)$ in gastrointestinal mucosa associated lymphoid tissue lymphoma. J Clin Pathol 2003;56:36-42.

24. Zullo A, Hassan C, Cristofari F. Gastric low-grade mucosalassociated lymphoid tissue-lymphoma: Helicobacter pylori and beyond. World J Gastrointest Oncol 2010;2:181-6.

25. Kolve M, Fischbach W, Greiner A, et al. Differences in endoscopic and clinicopathological features of primary and secondary gastric non-Hodgkin's lymphoma. Gastrointest Endosc 1999;49:307-15.

26. Ferreri AJM, Montalbán C. Primary diffuse large B-cell lymphoma of the stomach. Crit Rev Oncol Hematol 2007;63:65-71.

27. Ponzoni M, Ferreri AJM, Pruneri G, et al. Prognostic value of BCL-6, CD10 and CD38 immunoreactivity in stage I-II gastric lymphomas: identification of a subset of CD10+ large B-cell lymphomas with a favorable outcome. Int J Cancer 2003;106:288-91.

28. Hayashi D, Devenney-Cakir B, Lee JC, et al. MucosaAssociated lymphoid tissue lymphoma: multimodality imaging and histopathologic correlation. AJR Am J Roentgenol 2010;195:W105-17.

29. d'Amore F, Brincker H, Grønbaek K, et al. Non-Hodgkin's lymphoma of the gastrointestinal tract: a population-based analysis of incidence, geographic distribution, clinicopathologic presentation features, and prognosis. Danish Iymphoma Study Group. J Clin Oncol 1994;12:1673-84.

30. Zhu L, Wu G, Ghimire P, et al. Ct features of peripheral T-cell lymphoma in the gastrointestinal tract in Chinese population and literature review. J Med Imaging Radiat Oncol 2012;56:143-50.

31. Kim DH, Lee D, Kim JW, et al. Endoscopic and clinical analysis of primary T-cell lymphoma of the gastrointestinal tract according to pathological subtype. J Gastroenterol Hepatol 2014;29:934-43.

32. Ayub A, Rehmani S, Al-Ayoubi AM, et al. Primary Non-Hodgkin's Lymphoma of the Gallbladder: A Population-based Analysis. Anticancer Res 2017;37:2581-6.

33. Honda M, Furuta $\mathrm{Y}, \mathrm{Naoe} \mathrm{H}$, et al. Primary mucosa-associated lymphoid tissue (MALT) lymphoma of the gallbladder and review of the literature. BMJ Case Rep 2017;82:pii: bcr-2017-220161.

34. Al-Katib S, Colvin R, Sokhandon F. Intravascular large B-cell lymphoma presenting with diffuse gallbladder wall thickening: a case report and literature review. Case Rep Radiol 2018;2018:2494207

35. Zakaria A, Al-Obeidi S, Daradkeh S. Primary non-Hodgkin's lymphoma of the common bile duct: a case report and literature review. Asian J Surg 2017;40:81-7.

36. Mouchli MA, Kurtin PJ, LaRusso NF. A 59-year-old man with new jaundice. Gastroenterology 2018;154:2035-6.

37. Yu L, Chen Y, Xing L. Primary pancreatic lymphoma: two case reports and a literature review. Onco Targets Ther 2017;10:1687-94.

38. Kumar Padhan R, Padhan RK, Das P S. Primary hepatic lymphoma. Trop Gastroenterol 2015;36:14-20.

39. Jaffe ES, Harris NL, Stein $\mathrm{H}$, et al. Classification of lymphoid neoplasms: the microscope as a tool for disease discovery. Blood 2008;112:4384-99.

40. Du M-Q, Atherton JC. Molecular subtyping of gastric MALT lymphomas: implications for prognosis and management. Gut 2006;55:886-93

41. Welaya K, Casulo C. Follicular lymphoma: redefining prognosis, current treatment options, and unmet needs. Hematol Oncol Clin North Am 2019;33:627-38.

42. Young RC, Longo DL, Glatstein E, et al. The treatment of indolent lymphomas: watchful waiting $\mathrm{V}$ aggressive combined modality treatment. Semin Hematol 1988;25(2 Suppl 2):11-16.
43. Koniaris LG, Drugas G, Katzman PJ, et al. Management of gastrointestinal lymphoma. J Am Coll Surg 2003;197:127-41.

44. Zullo A, Hassan C, Cristofari F, et al. Effects of Helicobacter pylori eradication on early stage gastric mucosa-associated lymphoid tissue lymphoma. Clin Gastroenterol Hepatol 2010;8:105-10.

45. Matysiak-Budnik T, Fabiani B, Hennequin C, et al. Gastrointestinal lymphomas: French intergroup clinical practice recommendations for diagnosis, treatment and follow-up (SNFGE, FFCD, GERCOR, UNICANCER, SFCD, SFED, SFRO, SFH). Dig Liver Dis 2018;50:124-31.

46. Thieblemont C, Zucca E. Clinical aspects and therapy of gastrointestinal MALT Iymphoma. Best Pract Res Clin Haemato 2017;30:109-17.

47. Tondini C, Balzarotti M, Santoro A, et al. Initial chemotherapy for primary resectable large-cell lymphoma of the stomach. Ann Oncol 1997;8:497-9.

48. Ferrer AJM, Cordio S, Ponzoni M, et al. Non-surgical treatment with primary chemotherapy, with or without radiation therapy, of stage I-II high-grade gastric Iymphoma. Leuk Lymphoma 1999;33:531-41

49. Mishima Y, Terui Y, Yokoyama M, et al. R-CHOP with doseattenuated radiation therapy could induce good prognosis in gastric diffuse large B cell lymphoma. Exp Hematol Oncol 2012;1.

50. Lightner AL, Shannon E, Gibbons MM, et al. Primary Gastrointestinal Non-Hodgkin's Lymphoma of the Small and Large Intestines: a Systematic Review. J Gastrointest Surg 2016:20:827-39.

51. Daum S, Ullrich R, Heise W, et al. Intestinal Non-Hodgkin's Lymphoma: A Multicenter Prospective Clinical Study From the German Study Group on Intestinal Non-Hodgkin's Lymphoma. J Clin Oncol 2003;21:2740-6.

52. Zing NPC, Fischer T, Zain J, et al. Peripheral T-cell lymphomas: incorporating new developments in diagnostics, prognostication, and treatment into clinical Practice-PART 2: ENKTL, EATL, indolent T-cell LDP of the Gi tract, ATLL, and Hepatosplenic T-cell lymphoma. Oncology 2018;32:e83-9.

53. Nijeboer P, Malamut G, Mulder CJ, et al. Enteropathy-associated T-cell lymphoma: improving treatment strategies. Dig Dis 2015;33:231-5.

54. Gleeson M, Peckitt C, To YM, et al. CHOP versus GEM-P in previously untreated patients with peripheral T-cell lymphoma (CHEMO-T): a phase 2, multicentre, randomised, open-label trial. Lancet Haematol 2018;5:e190-200.

55. Tatar C, Yavas M, Akkus O, et al. Intestinal perforation that developed after chemotherapy in a patient diagnosed with nonHodgkin lymphoma: a case report and review of literature. Int J Surg Case Rep 2017;39:321-3.

56. Schizas D, Ntanasis-Stathopoulos I, Tsilimigras DI, et al. The role of endoscopic ultrasound in the diagnosis and management of primary gastric lymphoma. Gastroenterol Res Pract 2017;2017:2397430

57. van Gils T, Nijeboer P, Overbeek LI, et al. Risks for lymphoma and gastrointestinal carcinoma in patients with newly diagnosed adultonset celiac disease: consequences for follow-up: celiac disease, lymphoma and Gi carcinoma. United European Gastroenterol $J$ 2018;6:1485-95.

58. Elkholy S, Mogawer S, Farag A. Nodular Lymphoid Hyperplasia of the Gastrointestinal Tract : a comprehensive review. Acta Gastroenterol Belg 2017;80:405-10.

59. Albuquerque A. Nodular lymphoid hyperplasia in the gastrointestinal tract in adult patients: a review. World J Gastrointest Endosc 2014;6:534-40 